\title{
Direct Muscarinic Cholinergic Inhibition of Hepatic Glucose Production in Humans
}

Patrick J. Boyle, Stephen B. Liggett, Suresh D. Shah, and Philip E. Cryer

Metabolism Division of the Department of Medicine, and the General Clinical Research Center and Diabetes

Research and Training Center, Washington University School of Medicine, St. Louis, Missouri 63110

\begin{abstract}
To explore the potential role of the parasympathetic nervous system in human glucoregulatory physiology, responses to the muscarinic cholinergic agonist bethanechol (5.0 mg s.c.) and antagonist atropine (1.0 $\mathrm{mg}$ i.v.) were measured in normal humans. There were no changes in the plasma glucose concentration or rates of glucose production or utilization following atropine administration. After bethanechol administration there were no changes in the plasma glucose concentration or fluxes despite increments in plasma glucagon (75 \pm 7 to $103 \pm 10$ $\mathrm{pg} / \mathrm{ml}, P<0.02)$. There were no changes in insulin or $C$-peptide levels. To test the hypothesis that direct muscarinic inhibition of glucose production was offset by an indirect action of the agonist, specifically increased glucagon secretion with consequent stimulation of glucose production, bethanechol was administered while glucagon levels were held constant with the islet clamp technique (somatostatin infusion with insulin, glucagon and growth hormone replacement at fixed rates). Under that condition the muscarinic agonist induced a $25 \%$ decrement in the plasma glucose concentration $(101 \pm 8$ to $75 \pm 8 \mathrm{mg} / \mathrm{dl}, P$ $<0.05$ ). When compared with separate clamp control studies (with placebo rather than bethanechol injection) both the rate of glucose production and the glucose concentration were reduced $(P<0.05)$ following bethanechol injection; the rate of glucose utilization was unaltered. Thus, we conclude: Withdrawal of parasympathetic tone does not appear to be an important glucoregulatory process in humans. Direct muscarinic cholinergic inhibition of hepatic glucose production occurs in humans but during generalized muscarinic activation this is offset by an indirect muscarinic action, increased glucagon secretion with consequent stimulation of glucose production. Thus, particularly if regional neuronal firing occurs, the parasympathetic nervous system may play an important role in human glucoregulatory physiology.
\end{abstract}

\section{Introduction}

The potential role of the parasympathetic nervous system in human glucoregulatory physiology and pathophysiology has not been explored in depth. This contrasts with the role of the sympathochromaffin system, including the sympathetic nervous system, which has been studied rather extensively (1). In

Address reprint requests to Dr. Cryer, Metabolism Division (Box 8127), Washington University School of Medicine, 660 South Euclid Avenue, St. Louis, MO 63110.

Received for publication 14 December 1987 and in revised form 7 March 1988.

J. Clin. Invest.

(C) The American Society for Clinical Investigation, Inc. 0021-9738/88/08/0445/05 \$2.00

Volume 82, August 1988, 445-449 animals both the liver $(2,3)$ and the pancreatic islets (4-6) receive cholinergic, as well as adrenergic and peptidergic, innervation, and stimulation of parasympathetic nerves has been reported to reduce hepatic glucose output $(2,3,7)$. Further, administration of the muscarinic antagonist atropine appeared to increase hepatic glucose release in dogs (8). However, neither the acetylcholinesterase inhibitor edrophonium $(9,10)$ nor the muscarinic agonist bethanechol (9) have been found to alter the plasma glucose concentration in humans.

The concept of direct and indirect (hormone mediated) metabolic actions of a given glucoregulatory factor, which emerged from studies of the mechanisms of the hyperglycemic effect of the catecholamines (1), may also be relevant to the study of potential glucoregulatory effects of the parasympathetic nervous system. For example, the hyperglycemic response to epinephrine is the result of both its direct action to stimulate hepatic glucose production and limit glucose utilization and the indirect action of the hormone to restrain insulin secretion $(1,11)$. Indeed, modulation of insulin secretion is a critical glucoregulatory event in that restraint of insulin secretion by epinephrine permits the hyperglycemic response to the hormone to occur, but a small increase in insulin secretion limits the magnitude of the glycemic response (12).

We tested the hypothesis that muscarinic cholinergic agonism inhibits hepatic glucose production through direct actions, indirect actions or both direct and indirect actions in normal humans. To do so, we measured responses to the muscarinic agonist bethanechol (and the muscarinic antagonist atropine) under conditions in which both direct and indirect actions were expected to be operative, and the responses to bethanechol under conditions in which potential indirect actions were controlled. The latter was accomplished with the islet clamp technique (12-14), somatostatin infusion with insulin, glucagon and growth hormone replacement, which holds the levels of islet hormones including glucagon and insulin constant before and after an intervention. This approach permitted demonstration of direct muscarinic cholinergic inhibition of hepatic glucose production in humans.

\section{Methods}

Subjects. Nine healthy adults (six men and three women) gave their written consent to participate in these studies which were approved by the Washington University Human Studies Committee and conducted on the Washington University General Clinical Research Center. Six subjects participated in each of the two protocols. Thus, three subjects participated in both protocols. The participants' ages ranged from 20 to $25 \mathrm{yr}$; all were within $20 \%$ of their ideal body weight (Metropolitan Life Insurance Co. Tables, 1983).

Protocols. All studies were performed after an overnight fast of at least $12 \mathrm{~h}$. On the day of study two intravenous lines, one for infusions and one for sampling, were inserted by 0800 hours. The time of first drug administration was designated $0 \mathrm{~min}$. At $-120 \mathrm{~min}$ a priming dose of $20 \mu \mathrm{Ci}$ of $3-\left[{ }^{3} \mathrm{H}\right]$ glucose $(11.5 \mathrm{Ci} / \mathrm{mmol}$, New England Nuclear, Boston, MA) was administered intravenously; a dose $0.2 \mu \mathrm{Ci} / \mathrm{min}$ was 
infused intravenously throughout thereafter. Blood samples were obtained at 10 -min intervals from -30 through $240 \mathrm{~min}$ (first protocol) or $120 \mathrm{~min}$ (second protocol), distributed to the appropriate tubes, kept on ice and centrifuged promptly. The supernatants were then frozen for subsequent analysis. Heart rate and blood pressure were recorded (Dinamap Vital Signs Monitor, model 1846; Critikon Inc., Tampa, FL) at 10-min intervals; the electrocardiogram was monitored continuously.

In the first protocol $5.0 \mathrm{mg}$ of bethanechol hydrochloride (Merck Sharp and Dohme, West Point, PA), a muscarinic agonist, was administered subcutaneously at $0 \mathrm{~min}$ and $1.0 \mathrm{mg}$ of atropine, a muscarinic antagonist, was administered intravenously over $5 \mathrm{~min}$ starting at $120 \mathrm{~min}$.

In the second protocol two studies, one with bethanechol administration (clamp plus bethanechol) and one with saline placebo administration (clamp control), were performed during islet clamps in each subject. The islet clamps involved intravenous infusion of somatostatin (Peninsula Laboratories, Belmont, CA), $250 \mu \mathrm{g} / \mathrm{h}$, glucagon (Eli Lilly and Co., Indianapolis, IN), $1.0 \mathrm{ng} \cdot \mathrm{kg}^{-1} \cdot \mathrm{min}^{-1}$, and methionyl growth hormone (Genentech Corp., San Francisco, CA), 4.0 $\mathrm{ng} \cdot \mathrm{kg}^{-1} \cdot \mathrm{min}^{-1}$, in a single solution prepared in $1 \%$ human serum albumin in saline. Regular insulin (Novolin; Squibb-Novo, Basgvaerd, Denmark), also prepared in $1 \%$ human serum albumin, was infused initially at a variable rate with a syringe infusion pump (Harvard Apparatus Inc., Natick, MA). The insulin infusion rate was adjusted by the investigator at 10 -min intervals to achieve steady state plasma glucose concentrations of $\sim 90 \mathrm{mg} / \mathrm{dl}$. Thus, the islet clamp technique used here differed from that used previously $(12-14)$ in that growth hormone was also replaced and initial insulin adjustments were made manually by the investigator rather than with a Biostator. When stable glucose levels were achieved, generally after 3-6 h, the insulin dose was fixed. If glucose levels were stable over the next hour, sampling ( -30 $\mathrm{min}$ ) was then begun and continued through $120 \mathrm{~min}$. Bethanechol or placebo was administered at $0 \mathrm{~min}$. The sequence of the clamp control and clamp plus bethanechol studies was varied.

Analytical methods. Plasma glucose was measured with a glucose oxidase method using a glucose analyzer (Beckman Insțruments Inc., Fullerton, CA). Plasma insulin and C-peptide (15), glucagon (16), cortisol (17), growth hormone (18) and pancreatic polypeptide (19) were measured with radioimmunoassays, epinephrine and norepinephrine with a single isotope derivative (radioenzymatic) method (20). Glucagon was measured on unextracted plasma using an antiserum (G15) provided by Dr. Jonathan Jaspan (University of Chicago). Serum free fatty acids were measured with a colorimetric method (21). Microfluorimetric methods were used to measure blood $\beta$-hydroxybutyrate (22), lactate (23), and alanine (24). Plasma for glucose radioactivity was precipitated with polyethylene glycol and the supernatant decanted, dried, and reconstituted in distilled water before scintillation counting; glucose production and utilization rates were calculated as described previously (25).

Statistical methods. Dața are presented as the mean plus or minus the standard error. For hormone and metabolic intermediate concentrations comparisons of interest were tested for significance with a $t$ test for paired data. For the clamp studies the rates of decline in plasma glucose (initial slopes) were determined using a linear fit of each individual's data from 0 through $60 \mathrm{~min}$; slopes from the clamp control and clamp plus bethanechol studies were also compared with a $t$ test. Areas under the curve for rates of glucose production and utilization were derived from normalized data (i.e., after adjustments for differences at $0 \mathrm{~min}$ ) for each individual in each study by applying sequential trapezoidal summation between observation points. Those from the clamp control and clamp plus bethanechol studies were then compared with a Wilcoxon signed rank test.

\section{Results}

\section{Protocol 1: Bethanechol and atropine administration}

Plasma glucose concentrations and rates of glucose production and utilization were unchanged following bethanechol admin- istration and following atropine administration (Fig. 1). Plasma pancreatic polypeptide increased from $65 \pm 5 \mathrm{pg} / \mathrm{ml}$ to a peak of $109 \pm 1(P<0.01) 40 \mathrm{~min}$ after bethanechol injection; it was unchanged following atropine administration (Fig. 1). Neither plasma insulin nor C-peptide levels were altered by bethanechol or atropine administration, but plasma glucagon increased from $75 \pm 7 \mathrm{pg} / \mathrm{ml}$ to a peak of $103 \pm 10 \mathrm{pg} / \mathrm{ml}(P$ $<0.02$ ) 60 min after bethanechol injection (Fig. 1).

Apparent increments in plasma norepinephrine $(236 \pm 36$ to $399 \pm 121 \mathrm{pg} / \mathrm{ml}$ ) after bethanechol injection and in plasma epinephrine $(28 \pm 8$ to $93 \pm 32 \mathrm{pg} / \mathrm{ml})$ after atropine administration (Fig. 2) were not significant statistically, nor was an apparent increase in plasma cortisol (from $6.2 \pm 1.3$ to $15.1 \pm 5.0$ $\mu \mathrm{g} / \mathrm{dl}$ ) after atropine (Fig. 2). There were no systematic changes in plasma growth hormone (Fig. 2). Heart rate increased from $60 \pm 4 \mathrm{bpm}$ to a peak of $96 \pm 5 \mathrm{bpm}(P<0.01) 20 \mathrm{~min}$ after atropine administration (Fig. 2).

Apparent increments in serum free fatty acid and blood $\beta$-hydroxybutyrate concentrations after bethanechol injection, and in free fatty acid concentrations following atropine administration, were not significant statistically (Fig. 3). Blood lactate and alanine levels tended to decrease over time but were not altered significantly by bethanechol or atropine administration (Fig. 3).

Symptoms that followed bethanechol administration included lacrimation sweating, urinary urgency, and abdominal discomfort. Xerostomia followed atropine administration.

\section{Protocol 2: Islet clamps with and without bethanechol}

Mean plasma glucose concentrations and rates of glucose production and utilization did not change during the clamp control placebo study. In contrast, mean plasma glucose decreased from $101 \pm 8$ to $82 \pm 6 \mathrm{mg} / \mathrm{dl}$ at $60 \mathrm{~min}$ and $75 \pm 7 \mathrm{mg} / \mathrm{dl}$ at 120 min (both $P<0.05$ ) after bethanechol injection in the clamp plus bethanechol study (Fig. 4). Both the initial (first $60 \mathrm{~min}$ ) rate of decline (slope) of the individual plasma glucose concentrations and the area under the glucose production rate curves differed significantly $(P<0.05)$ between the clamp
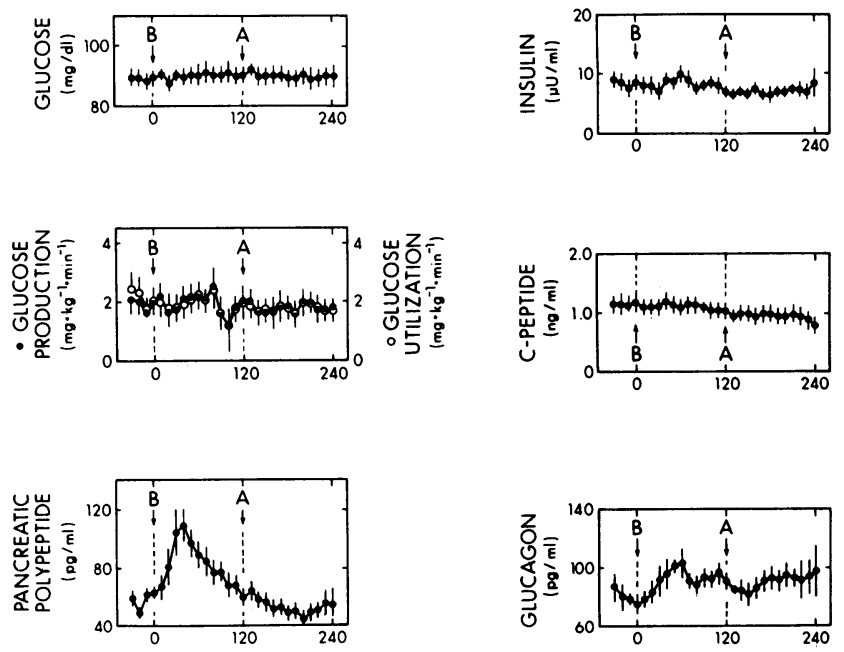

TIME $(\min )$

Figure 1. Mean ( \pm SE) plasma glucose concentrations, rates of glucose production and utilization, and plasma concentrations of pancreatic polypeptide, insulin, C-peptide and glucagon following subcutaneous injection of bethanechol $(B)$ and intravenous administration of atropine $(A)$ in normal humans. 

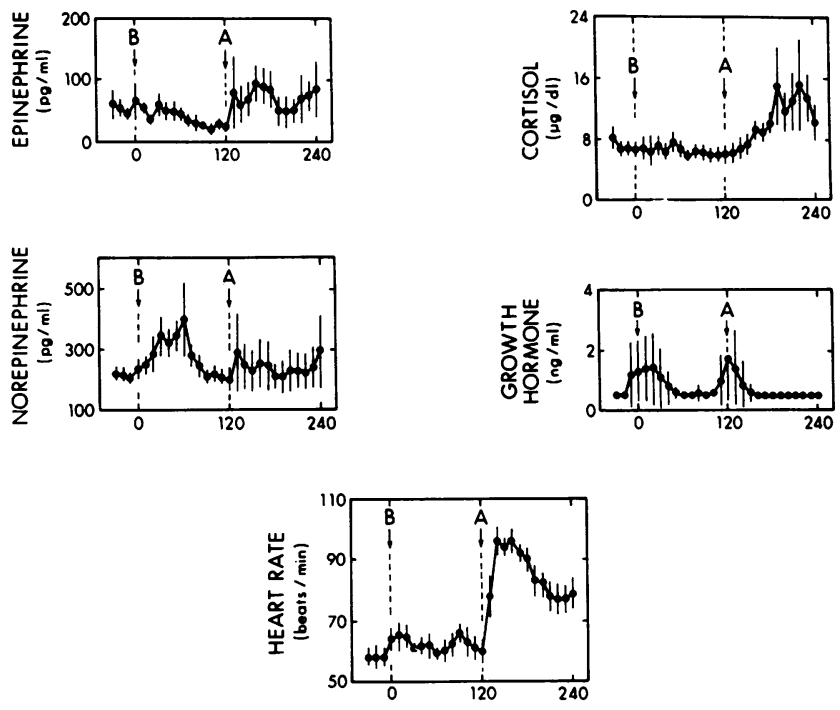

TIME (min)

Figure 2. Mean ( $\pm \mathrm{SE}$ ) plasma concentrations of epinephrine, norepinephrine, cortisol and growth hormone and mean heart rate following subcutaneous injection of bethanechol $(B)$ and intravenous administration of atropine $(A)$ in normal humans.

control and clamp plus bethanechol studies (Fig. 4). The corresponding slopes and areas under the curves for glucose utilization did not differ significantly between the clamp control and clamp plus bethanechol studies.

During the clamp control and clamp plus bethanechol studies plasma concentrations of C-peptide were suppressed and those of pancreatic polypeptide, insulin, and glucagon (Fig. 5) and of cortisol and growth hormone (Fig. 6) were unchanged. Apparent late increments in plasma epinephrine $(46 \pm 17$ to $155 \pm 47 \mathrm{pg} / \mathrm{ml})$ and early increments in plasma norepinephrine ( $170 \pm 9$ to $297 \pm 48 \mathrm{pg} / \mathrm{ml}$ ) following bethanechol injection (Fig. 6) were not significant statistically.

Serum free fatty acid and blood $\beta$-hydroxybutyrate, lactate, and alanine concentrations did not change after bethanechol injection during the clamp study (Fig. 7).

\section{Discussion}

The actions of acetylcholine released from postganglionic neurons of the parasympathetic nervous system are mediated
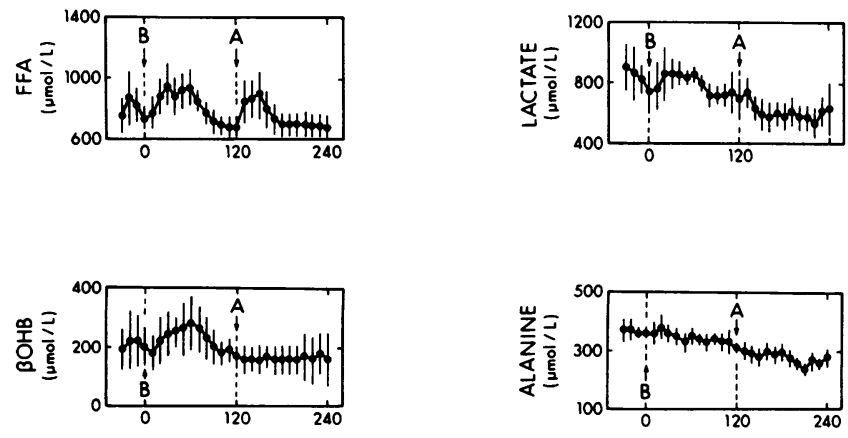

TIME $(\min )$

Figure 3. Mean $( \pm \mathrm{SE})$ serum free fatty acid and blood $\beta$-hydroxybutyrate, lactate, and alanine concentrations following subcutaneous injection of bethanechol and intravenous administration of atropine $(A)$ in normal humans.

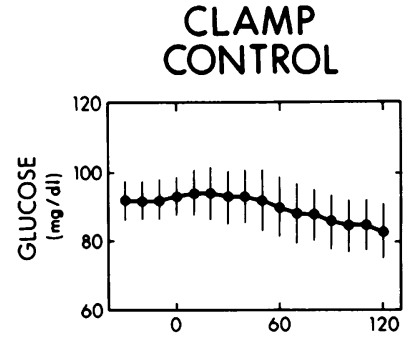

CLAMP + BETHANECHOL
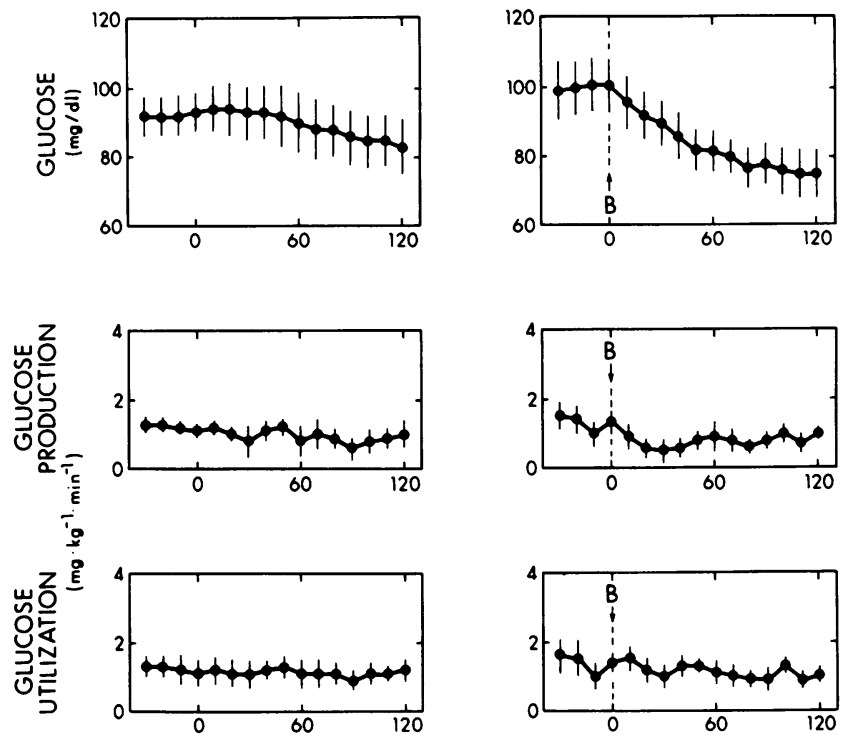

TIME $(\min$

Figure 4. Mean ( $\pm \mathrm{SE})$ plasma glucose concentrations and rates of glucose production and utilization during islet clamp studies with placebo injection (clamp control) and during islet clamp studies with bethanechol $(B)$ injection (clamp + bethanechol) in normal humans.

by muscarinic cholinergic receptors (26). To explore the potential role of the parasympathetic nervous system in human glucoregulatory physiology, we measured the responses to subcutaneous injection of the muscarinic agonist bethanechol and
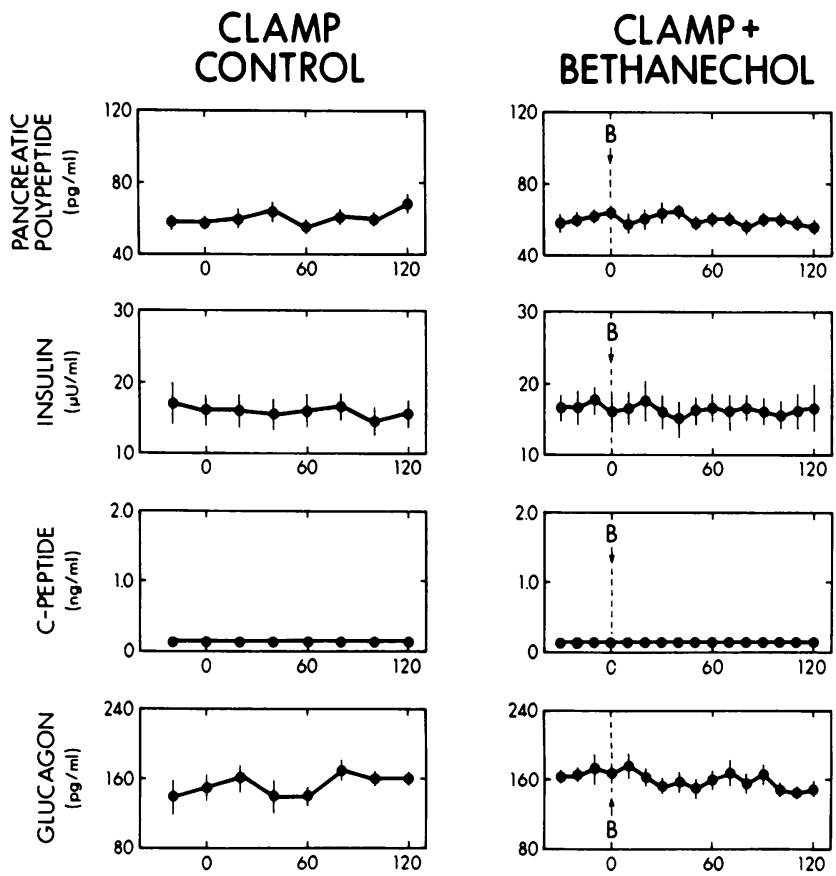

TIME (min)

Figure 5. Mean ( \pm SE) plasma pancreatic polypeptide, insulin, C-peptide and glucagon concentrations during islet clamp studies with placebo injection (clamp control) and during islet clamp studies with bethanechol $(B)$ injection (clamp + bethanechol) in normal humans. 

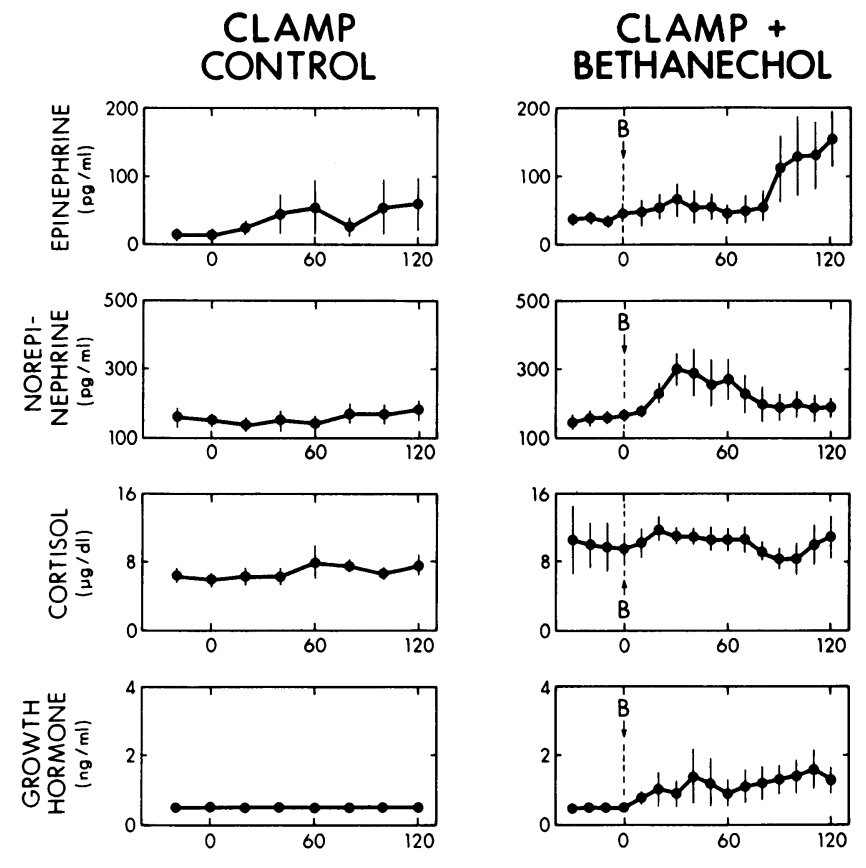

TIME (min)

Figure 6. Mean $( \pm \mathrm{SE})$ plasma epinephrine, norepinephrine, cortisol and growth hormone concentrations during islet clamp studies with placebo injection (clamp control, left) and during islet clamp studies with bethanechol $(B)$ injection (clamp + bethanechol) in normal humans.

to intravenous injection of the muscarinic antagonist atropine in normal humans. The adequacy of the doses used was evidenced by typical symptoms and a sharp increase in plasma pancreatic polypeptide concentrations following bethanechol administration, and by symptoms and a sharp increase in heart rates following atropine administration.

There was no demonstrable effect of muscarinic cholinergic antagonism with atropine on glucoregulation in overnight fasted subjects. Thus, withdrawal of parasympathetic tone does not appear to be an important glucoregulatory process in humans. The same can be said of sympathochromaffin, in-

\section{CLAMP + BETHANECHOL}
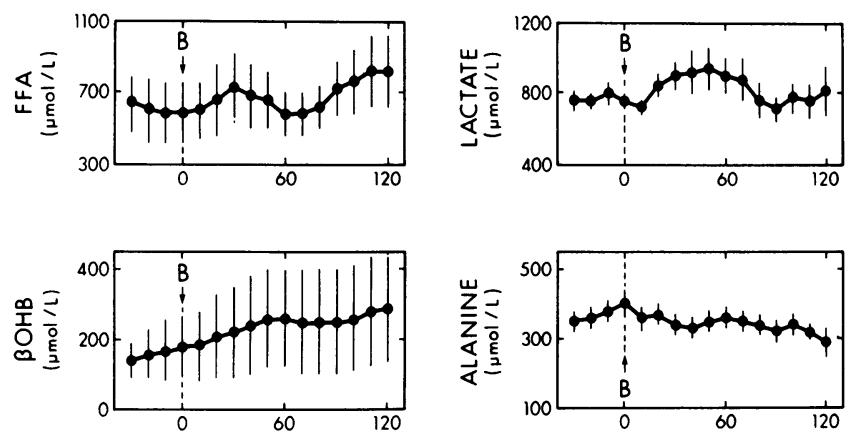

TIME (min)

Figure 7. Mean $( \pm \mathrm{SE})$ serum free fatty acid and blood $\beta$-hydroxybutyrate, lactate and alanine concentrations during islet clamp studies with bethanechol $(B)$ injection (clamp + bethanechol) in normal humans. cluding sympathetic nervous system, tone since adrenergic blockade per se does not alter glucoregulation in postabsorptive humans $(27,28)$.

There was also no net effect of generalized muscarinic agonism with bethanechol on plasma glucose concentrations or glucose kinetics. However, it was conceivable that a direct action of muscarinic activation to inhibit hepatic glucose production was offset by an indirect action of muscarinic activation, specifically the demonstrated stimulation of glucagon secretion which would be expected to stimulate hepatic glucose production. To test this possibility we used the islet clamp technique (12-14) to hold glucagon (as well as insulin, pancreatic polypeptide and growth hormone) levels constant before and after bethanechol injection. When an increase in glucagon secretion was prevented with this technique, muscarinic agonism resulted in a sharp initial decrease in hepatic glucose production and a consequent $25 \%$ fall in the plasma glucose concentration, changes that did not occur during control studies with the clamp and placebo injection. Thus, direct muscarinic cholinergic inhibition of hepatic glucose production occurs in humans. This finding is consistent with the data of Gardeman and Jungermann (7). They found that glucagon-stimulated glucose release from perfused rat livers was reduced by vagal nerve stimulation (in the presence of adrenergic antagonists) and that this effect was prevented by atropine. Therefore, particularly if regional neuronal firing (to the liver and to the pancreatic islets) occurs, the present data suggest that the parasympathetic nervous system may play an important physiologic role in human glucoregulation. Even if parasympathetic firing were more generalized, it is conceivable that it might alter net hepatic glucose production. We studied the metabolic response to a single dose of bethanechol. The dose-response relationships for direct inhibition and for indirect stimulation of hepatic glucose production were not determined, and might differ. Therefore, it is theoretically possible that varying levels of parasympathetic neural activity, even if generalized, might have different effects on the two processes resulting in a net change in hepatic glucose production.

Clearly, the present data do not establish a physiologic role for the parasympathetic nervous system in human glucoregulation, although they raise that possibility. Further studies will be required to determine whether it does, or does not. We believe that such studies are warranted, since parasympathetic activity changes during dynamic metabolic events such as hypoglycemia (29) and even ingestion of a meal $(6,30,31)$.

In view of the demonstration of direct muscarinic cholinergic inhibition of hepatic glucose production in normal humans, one could speculate that parasympathetic neuropathy might contribute to excessive hepatic glucose production in affected patients with diabetes mellitus. That speculation should be tempered, however, by the absence of a demonstrable effect of antagonism of basal parasympathetic tone on glucose production. It is conceivable, however, that reduced parasympathetic limitation of increments in glucose production might result in excessive hyperglycemia under dynamic conditions in affected patients.

Finally, we anticipated that muscarinic agonism would result in increased secretion of insulin $(6,31-33)$, an indirect action that would, if anything, have augmented a decrement in hepatic glucose production. However, the plasma concentrations of insulin and C-peptide were not altered by bethanechol injection, and hepatic glucose production did not fall, in the initial protocol in which glucagon secretion increased. This 
supports the conclusion that changes in the secretion of glucagon, rather than insulin, offset direct actions of muscarinic agonism on hepatic glucose production.

In summary, the data demonstrate that direct muscarinic cholinergic inhibition of hepatic glucose production occurs in humans. During generalized muscarinic activation this is counteracted by an indirect glucoregulatory action, stimulation of glucagon secretion. Thus, particularly if regional neuronal firing (to the liver and to the pancreatic islets) occurs, the parasympathetic nervous system may play an important role in human glucoregulatory physiology.

\section{Acknowledgments}

The authors acknowledge the technical assistance of Mr. Krishan Jethi, Ms. Susan Allen, Ms. Alka Bansal, Mr. Geoffrey Boyd, Ms. Shirley Hill, Ms. Joy Brothers, Ms. Galina Leybovich, Ms. Zina Lubovich, and Mr. Abbey Akinola. The assistance of the nursing staff of the Washington University General Clinical Research Center, particularly Ms. Mary Ann Tueth and Ms. Virginia Bischof, and the secretarial and administrative assistance of Ms. Theresa Lautner are also gratefully acknowledged.

Supported in part by U. S. Public Health Service grants DK-27085, DK-20579, and RR-00036.

\section{References}

1. Clutter, W. E., R. A. Rizza, J. E. Gerich, and P. E. Cryer. 1988. Regulation of glucose metabolism by sympathochromaffin catecholamines. Diabetes/Metab. Rev. 4:1-15.

2. Lautt, W. W. 1980. Hepatic nerves: a review of their functions and effects. Can. J. Physiol. Pharmacol. 58:105-123.

3. Lautt, W. W. 1983. Afferent and efferent neural roles in liver function. Prog. Neurobiol. 21:323-348.

4. Esterhuizen, A. C., T. L. B. Spriggs, and J. D. Lever. 1968. Nature of islet cell innervation in cat pancreas. Diabetes. 17:33-36.

5. Miller, R. E. 1981. Pancreatic neuroendocrinology: Peripheral neural mechanisms in the regulation of the islets of Langerhans. Endocrine Rev. 2:471-494.

6. Ahren, B., G. J. Taborsky, and D. Porte, Jr. 1986. Neuropeptidergic versus cholinergic and adrenergic regulation of islet hormone secretion. Diabetologia. 29:827-836.

7. Gardemann, A., and K. Jungerman. 1986. Control of glucose balance in the perfused rat liver by the parasympathetic innervation. Biol. Chem. Hoppe-Seyler. 367:559-566.

8. Chap, Z., T. Ishida, J. Chou, R. Lewis, C. Hartley, M. Entman, and J. B. Field. 1985. Effects of atropine and gastric inhibitory polypeptide on hepatic glucose uptake and insulin extraction in conscious dogs. J. Clin. Invest. 76:1174-1181.

9. Palmer, J. P., P. L. Werner, P. Hollander, and J. W. Ensinck. 1979. Evaluation of the control of glucagon secretion by the parasympathetic nervous system in man. Metab. Clin. Exp. 28:549-557.

10. Leveston, S. A., S. D. Shah, and P. E. Cryer. 1979. Cholinergic stimulation of norepinephrine release in man. J. Clin. Invest. 64:374380.

11. Altszuler, N., R. Steele, I. Rathgeb, and R. C. DeBodo. 1967. Glucose metabolism and plasma insulin level during epinephrine infusion in the dog. Am. J. Physiol. 212:677-682.

12. Berk, M. A., W. E. Clutter, D. Skor, S. D. Shah, R. P. Gingerich, C. A. Parvin, and P. E. Cryer. 1985. Enhanced glycemic responsiveness to epinephrine in insulin dependent diabetes mellitus is the result of the inability to secrete insulin. J. Clin. Invest. 75:1842-1851.

13. Hoelzer, D. R., G. P. Dalsky, W. E. Clutter, S. D. Shah, J. O. Holloszy, and P. E. Cryer. 1986. Glucoregulation during exercise. Hypoglycemia is prevented by redundant glucoregulatory systems, sym- pathochromaffin activation and changes in islet hormone secretion. $J$. Clin. Invest. 77:212-221.

14. Hoelzer, D. R., G. P. Dalsky, N. S. Schwartz, W. E. Clutter, S. D. Shah, J. O. Holloszy, and P. E. Cryer. 1986. Epinephrine is not critical to prevention of hypoglycemia during exercise in humans. Am. J. Physiol. 251:E104-E110.

15. Kuzuya, H., P. M. Blix, D. L. Horwitz, D. F. Steiner, and A. H. Rubenstein. 1977. Determination of free and total insulin and C-peptide in insulin treated diabetics. Diabetes. 26:22-29.

16. Ensinck, J. W. 1983. Immunoassays for glucagon. In Glucagon. Handbook of Experimental Pharmacology. Vol. 66. P. Lefebvre, editor. Springer-Verlag, New York. 203-221.

17. Farmer, R. W., and C. E. Pierce. 1974. Plasma cortisol determination: radioimmunoassay and competitive binding compared. Clin. Chem. 20:411-414.

18. Schalch, D., and M. Parker. 1964. A sensitive double antibody radioimmunoassay for growth hormone in plasma. Nature (Lond.). 203:1141-1142.

19. Gingerich, R., P. Lacy, R. E. Chance, and M. G. Johnson. 1978. Regional pancreatic concentration and in vitro secretion of canine pancreatic polypeptide, insulin and glucagon. Diabetes. 27:96-101.

20. Shah, S. D., W. E. Clutter, and P. E. Cryer. 1985. External and internal standards in the single isotope derivative (radioenzymatic) assay of plasma norepinephrine and epinephrine in normal humans and persons with diabetes or chronic renal failure. J. Lab. Clin. Med. 106:624-629.

21. Novak, M. 1965. Colorimetric ultramicro method for the determination of free fatty acids. J. Lipid Res. 6:431-433.

22. Pinter, J. D., J. A. Hayaski, and J. A. Watson. 1967. Enzymatic assay of glycerol, dihydroxyacetone and glyceraldehyde. Arch. Biochem. Biophys. 121:404-414.

23. Lowry, O. H., J. V. Passoneau, F. X. Hasselberger, and D. V. Schultz. 1964. Effect of ischemia on known substrates and co-factors of the glycolytic pathway of the brain. J. Biol. Chem. 239:18-30.

24. Cahill, G. F., Jr., M. G. Herrera, A. P. Morgan, J. S. Soeldner, J. Steinke, P. Levy, G. A. Rerchand, Jr., and D. M. Kipnis. 1966. Hormone-fuel interrelationships during fasting. J. Clin. Invest. 45:17511769.

25. Clutter, W. E., D. M. Bier, S. D. Shah, and P. E. Cryer. 1980. Epinephrine plasma metabolic clearance rates and physiologic thresholds for metabolic and hemodynamic actions in man. J. Clin. Invest. 66:94-101.

26. Taylor, P. 1980. Cholinergic agonists. In Goodman and Gilman's The Pharmacological Basis of Therapeutics. 6th Edition. A. G. Gilman, L. S. Goodman, and A. Gilman, editors. MacMillan Publishing Co., Inc., New York. 91-99.

27. Clarke, W. L., J. V. Santiago, L. Thomas, M. W. Haymond, E. Ben-Galim, and P. E. Cryer. 1979. Adrenergic mechanisms in recovery from hypoglycemia in man: Adrenergic blockade. Am. J. Physiol. 236:E147-E152.

28. Rizza, R. A., P. E. Cryer, and J. E. Gerich. 1979. Role of glucagon, epinephrine and growth hormone in human glucose counterregulation. J. Clin. Invest. 64:62-71.

29. Frier, B. M., R. J. M. Corrall, J. G. Ratcliffe, J. P. Ashby, and E. J. W. McClemont. 1981. Autonomic neural control mechanisms of substrate and hormonal responses to acute hypoglycaemia in man. Clin. Endocrinol. 14:425-433.

30. Schwartz, T. W. 1983. Pancreatic polypeptide: A hormone under vagal control. Gastroenterology. 85:1411-1425.

31. Strubbe, J. H. 1982. Effects of pancreas transplantation on insulin secretion in the rat during ingestion of varying glucose loads. Diabetologia. 22:354-357.

32. Sharp, R., S. Culbert, J. Cook, A. Jennings, and I. M. Burr. 1974. Cholinergic modification of glucose-induced biphasic insulin release in vitro. J. Clin. Invest. 53:710-716.

33. Frohman, L. A., E. Z. Ezdinli, and R. Javid. 1967. Effect of vagotomy and vagal stimulation on insulin secretion. Diabetes. 16:443-448. 